\title{
EDITORIAL
}

\section{What will junior editors add to Intensive Care Medicine?}

Julie Helms ${ }^{1,2^{*}}$ (1)

(C) 2018 Springer-Verlag GmbH Germany, part of Springer Nature and ESICM

Each month Intensive Care Medicine (ICM) provides a selection of high-quality publications covering all aspects of intensive care. A thorough scientific and editorial review process throughout the publication cycle guarantees its high level and has led to successive metric improvements over the last few years [1].

With the start of the 2018 school year, ICM pushes the challenge further to increase both the quality and the visibility of published articles. The editorial board of the journal is thus making a bold bet by getting younger and offering us a unique, attractive, and enriching experience by joining the ICM editorial board as "junior editors". So far, only few medical journals have offered such an opportunity to juniors, although it allows them to get experience with the editorial teams of a prestigious journal and it may become a rewarding experience for the journal, too [2-4]. While maybe promoting the next generation of editors, ICM indeed strongly believes that involving juniors in the publishing process will add to the quality of published articles. Junior editors will indeed be able to represent and provide feedback from the perspective of younger intensivists, identify unmet needs, and highlight authors' work in an original way.

\section{The whys and the wherefores}

From now on, the task of junior editors will be to ensure the promotion of newly published articles in ICM, to share the latest findings and bring major intensive care

*Correspondence: julie.helms@chru-strasbourg.fr

2 Hôpitaux Universitaires de Strasbourg, Service de Réanimation, Nouvel Hôpital Civil, 1 place de l'Hôpital, 67000 Strasbourg, France

Full author information is available at the end of the article

The members of the "ICM Junior Editors" are listed in Acknowledgements section. articles to the attention of the greatest number of intensivists, and to ultimately improve patient care.

We, junior editors, are four young intensivists in their thirties, three men and one woman, coming from Denmark, Italy, and France, and we have been chosen for our dynamism and motivation. We are working on various clinical and translational topics, including hemodynamic, hemostasis, sepsis and antimicrobials, inflammation, and organ failure. Using the strengths from our different backgrounds, our young age along with our open-mindedness and overwhelming dynamism will allow us both to keep the essential global vision to promote all types of articles, regardless of their topic, and to deploy an astounding energy to achieve the aforementioned task.

Our potential scope of action is wide and the task facing us is multifaceted. To achieve an efficient article promotion, we will mainly use available social media platforms (Fig. 1). We will thus be able to reach the regular ICM readers, but also more occasional ones, and those who may not have access to full-text articles via a personal or an institutional subscription. As the ICM "reader target" necessarily includes junior intensivists, but not solely, we will publish regular news on different types of social media, like Facebook and Twitter. Readers will therefore be promptly informed of the new publications from one of the more influential journals in intensive care and be able to read the full article right away.

Also striving to increase the general visibility and readability of these articles, we will provide the ICM readers new visual abstracts (Fig. 1). These graphical abstracts will be meant to convey the main findings of newly published articles, by shortly and clearly summarizing the key question being addressed and stating its main outcomes. Although the reader may thus understand and better remember the key message of an article in a glance, the aim of the visual abstract is to draw the attention of

\section{Springer}




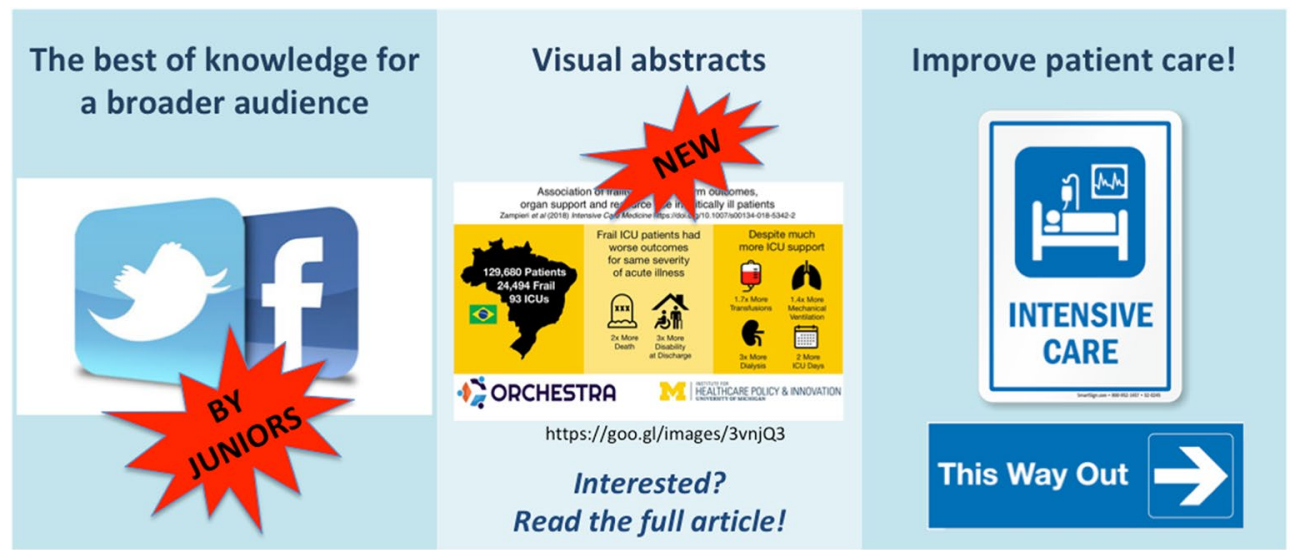

Fig. 1 What will junior editors add to Intensive Care Medicine?

potential readers and help them decide whether they want to proceed in reading the entire article.

The priority of ICM becomes the promotion of authors' articles and to satisfy our readers' curiosity! We, junior editors, are free to make any suggestions and to be creative and innovative. Our mission will therefore evolve over the coming months and may enrich content, for example with publication of updates on various topics as well as "pro and con" debates, publication of useful resources for authors, and the creation of a "Junior Editor Corner" on the future new ICM portal website where you will be able to find all the resources, and finally, organization of physical courses like a medical writing course for young doctors.

Do you have any ideas or suggestions? Please feel free to get in touch with us! We are now at the service of both ICM readers and authors, and will stay with you for the next three years!

\footnotetext{
Author details

${ }^{1}$ Université de Strasbourg (UNISTRA), Faculté de Médecine : ImmunoRhumatologie Moléculaire, INSERM UMR_S1109, LabEX TRANSPLANTEX, Centre de Recherche d'Immunologie et d'Hématologie, Fédération Hospitalo-Universitaire (FHU) OMICARE, Fédération de Médecine Translationnelle de Strasbourg (FMTS), 1 place de I'Hôpital, 67000 Strasbourg, France. ${ }^{2}$ Hôpitaux Universitaires de Strasbourg, Service de Réanimation, Nouvel Hôpital Civil, 1 place de l'Hôpital, 67000 Strasbourg, France.
}

\section{Acknowledgements}

ICM Junior Editors: Julie Helms, Université de Strasbourg (UNISTRA), Faculté de Médecine; Hôpitaux universitaires de Strasbourg, Service de Réanimation, Nouvel Hôpital Civil, 1 place de l'Hôpital, 67000 Strasbourg, France.
ImmunoRhumatologie Moléculaire, INSERM UMR_S1 109, LabEx TRANSPLANTEX, Centre de Recherche d'Immunologie et d'Hématologie, Faculté de Médecine, Fédération Hospitalo-Universitaire (FHU) OMICARE, Fédération de Médecine Translationnelle de Strasbourg (FMTS), Université de Strasbourg, 1 place de l'Hôpital, 67000 Strasbourg, France; Peter Buhl Hjortrup, Department of Intensive Care, Copenhagen University Hospital (Rigshospitalet), Blegdamsvej 9, 2100 København, Denmark, Peter.Buhl.Hjortrup@regionh.dk; Emmanuel Weiss, Department of anesthesiology and critical care, APHP, Beaujon hospital, Clichy, France: UMR 1149 Centre for Research on Inflammation; Inserm/Université Paris Diderot, 75018, Paris, France; Riccardo Pinciroli, School of Medicine and Surgery University Milano-Bicocca, 20854 Vedano al Lambro Monza et de la Brianza, Italy.

\section{Compliance with ethical standards}

\section{Conflicts of interest}

The authors declare that they have no conflicts of interest.

Received: 7 July 2018 Accepted: 19 September 2018

Published online: 28 September 2018

\section{References}

1. Azoulay E (2016) The editorial policy of intensive care medicine. Intensive Care Med 42:1313-1315

2. BMJ (2015) Applying for the 2015 Student BMJ Clegg Scholarship. http:// student.bmj.com/student/view-article.html?id\%C2\%BCsbmj.g6787. Accessed 16 Oct 2015

3. RCSI Student Medical Journal (2015) Junior editor post. http://www.rcsis mj.com/staff-positions/junior-editor. Accessed 16 Oct 2015

4. Bradley C, McGowan DR (2016) Observations: the introduction of "Junior Editor" posts within journals. J Grad Med Educ 8:110 